\title{
Students' opinions on working in rural practice in Slovenia
}

\author{
ROK PETROVCICA-F \\ Faculty of Medicine, University of Maribor, Slovenia
}

A - Study Design, B - Data Collection, C - Statistical Analysis, D - Data Interpretation, E - Manuscript Preparation, $\mathbf{F}$ - Literature Search, $\mathbf{G}$ - Funds Collection

Summary Background. All over the world, there is a lack of interest for specialty training in family medicine and for work in rural practice.

Objectives. The objective of our study was to survey the opinion of medical students of the Maribor Medical Faculty, Slovenia, about rural medicine.

Material and methods. This was a qualitative study. A semi-structured questionnaire with open-ended questions was used. In the period from December 2013 to February 2014, an electronic form was forwarded via e-mail to a stratified sample of 30 students of the Maribor Medical Faculty.

Results. 21 students $(70 \%)$ participated. Students stated several conditions that would make them work in rural practice. Their accounts were summarized as organizational (e.g. work hours, number of patients), infrastructural (e.g. equipment), local (e.g. cost of living) or personal (e.g. employment opportunities for their partner). Students associate rural practice with hard work, where physicians have to rely on their own abilities. Students see rural doctors as versatile personalities, knowledgeable, resourceful, optimistic, hard working and smart, but also as unambitious and elderly. Students connect rural practice with greater responsibility, diverse pathology, less availability of equipment and with less support for diagnostics. 15 (71\%) of the surveyed students want more emphasis placed on rural medicine in the undergraduate curriculum and electives. The reasons for accepting a rural scholarship would generally depend on the location for which it was offered and if it was tendered for the desired specialist training.

Conclusions. Students should be presented with opportunities for personal and professional development in rural areas during undergraduate programs. Rural scholarship programs need to be strengthened.

Key words: students, motivation, Slovenia, rural health, family practice, scholarship.

Petrovcic R. Students' opinions on working in rural practice in Slovenia. Fam Med Prim Care Rev 2016; 18(4): 448-454, doi: 10.5114/fmpcr.2016.63700.

\section{Background}

As in many other countries in the world, there is a lack of interest for specialist training in family medicine among the students and graduates of medical universities in Slovenia. An online survey, which was conducted in 2012 among young doctors, showed that out of 175 doctors who have not yet chosen their area of specialist training, only $5(2.9 \%)$ wished to specialize in family medicine [1]. There are important differences between regions in Slovenia. The situation is worse in more remote rural areas, where there is a big lack of doctors. This increases the workload of doctors working in rural practices. There are also problems with provision of some other primary health care services, such as physical therapy and preventive medicine [2]. In a study on the needs of rural practices in Slovenia, $82 \%$ of physicians agreed with the statement that they are overloaded with work and that there is a lack of health care workers in their area. As the main reasons for this situation, they cite covering too large a geographic area (62\%) and poor salary (35\%) [3]. There are different factors which influence an individual's decision concerning the type and place of their future work [4, 5]. Medical educators and policy makers have the greatest impact on the supply and retention of rural primary care physicians by developing programs to increase the number of medical school students with the background and career plans that make them more likely to pursue rural practice as a career. Curricular experiences and other factors can further increase these outcomes, especially by supporting those already likely to become rural primary care physicians [6]. Awareness of these factors is important in the quest for new strategies to attract more medical school graduates to work in rural practice. Medical school rural programs have produced a multifold increase in the supply of rural physicians, and widespread replication of these models could have a major impact on access to health care in thousands of rural communities [7]. To aid in the design of successful strategies to motivate students to work in rural practice, Wonca published a guidebook entitled the Rural Medical Education Guidebook. This manual is the result of the realization that medical education in rural areas is very useful for students and graduates, as it allows for a rich and diverse experience. It also alleviates the problem of the shortage of health workers in rural areas [8]. In line with the increased awareness of the problem of rural practices, we prepared a survey that studies the opinions of Slovenian medical students of the Maribor Medical School concerning work experience and medicine in rural areas. It represents a step towards raising awareness of rural medicine, expanding interest in this field among students and developing strategies for more rural oriented medical education in Slovenia.

\section{Objectives}

The overall purpose of the study was to survey the opinion of medical students about rural medicine. The purpose was to study opinions about rural medicine as a whole, 
along with rural medicine education and scholarship programs. On the basis of the collected opinion, education concerning rural medicine can be improved.

\section{Material and methods}

\section{Research design and setting}

This was a qualitative study. A questionnaire was prepared on the basis of similar research by Deaville, et al. [9] and Adams [10], as well as relevant questions. The questionnaire contained demographic questions, questions about one's attitude towards work after graduation and questions about opinions on rural practices. The questionnaire included open-ended question, which allowed free expression.

\section{Interviews}

A pre-prepared questionnaire with open-ended questions was converted to electronic form using the website www. 1 ka.si. In the period from December 2013 to February 2014, an electronic form was forwarded via e-mail to a sample of 30 interested students from all years of study at the Maribor Medical School with various experiences with rural practices. The electronic form assured anonymity.

\section{Data Analysis}

Methods of qualitative content analysis were used [11]. Transcripts of answers were read several times by the author of the study. Specific, significant and interesting themes were identified within the answers. In the next stage of the analysis, a list of all the themes was made. In the last stage of the analysis, the themes were grouped and further interpreted. For the purpose of this research paper, English translations of the answers were made.

\section{Ethical approval}

As stated by the Family Medicine Department of the Maribor Medical School, no ethical approval was needed.

\section{Results}

Out of 30 invited students, $21(70 \%)$ participated in the survey.

\section{Sociodemographic profile of surveyed students}

$6(29 \%)$ students live in cities, $6(29 \%)$ students live in suburban areas and $9(43 \%)$ in rural areas. 15 students did not engage in training or volunteer practice within the rural environment. 6 students were previously engaged in training or voluntary practice within the rural environment. 17 of the surveyed students had had interaction with, or personally knew, a doctor or a nurse from a rural environment.

\begin{tabular}{|l|l|l|}
\hline \multicolumn{3}{|l|}{ Table 1. Year of study } \\
\hline Year of study & Number of students & Percentage \\
\hline 1. & 1 & $5 \%$ \\
\hline 2. & 3 & $14 \%$ \\
\hline 3. & 5 & $24 \%$ \\
\hline 4. & 4 & $19 \%$ \\
\hline 5. & 0 & $0 \%$ \\
\hline 6. & 8 & $38 \%$ \\
\hline
\end{tabular}

\section{Specifics of rural practices}

Students associated rural practice with hard work, where the physician must rely on their own abilities. The work is connected with greater responsibility, diverse pathology, less equipment and less favorable diagnoses. Students anticipate a lot of improvisation in the work and little possibilities for consultation with other care providers. Positive associations of rural practice were less work, which leaves more free time for the doctor. The connection between the patient and the doctor were assumed as better compared to city practices, and greater appreciation was expected from the patient. Many students connected the countryside with a beautiful, clean and peaceful environment, where the pace of life is slower but offers less personal and family privacy.

\begin{tabular}{|l|l|}
\hline \multicolumn{2}{|l|}{ Table 2. Associations } \\
\hline Positive associations & Negative associations \\
\hline Less work & Hard work \\
\hline More free time & Greater responsibility \\
\hline $\begin{array}{l}\text { Better connection with } \\
\text { patients }\end{array}$ & Less equipment \\
\hline Peaceful environment & Less favorable diagnoses \\
\hline & A lot of improvisation \\
\hline & $\begin{array}{l}\text { Little consultation possibili- } \\
\text { ties }\end{array}$ \\
\hline & Less privacy \\
\hline
\end{tabular}

- "...practice, where all local people know you and come to you at any time, even after hours. You work in a beautiful, peaceful location, between the trees, where the air is clean..." ( $\mathrm{F}$, 6th year).

- "...in the morning, you drink coffee with your nurse, then you work hard, go out on house calls... people love you... people know everything about you" ( $\mathrm{F}$, 6th year).

\section{The role of rural practices in the medical system}

Students generally recognized the role of rural practices in the context of health services as very important. Rural practices were seen as important in many areas of prevention, education, cure and palliative care. Among the most important roles of rural practices as institutions, they listed provision of 24-hour emergency medical care for all citizens, irrespective of their location and distance from medical care. Students highlighted the importance of rural practices as the first point of contact with the health care system, which was especially characteristic of rural practices in remote areas.

- "...represent the patient's first contact with the health care system. As such, they have the most direct access and generally have a wider view of the patient's problems. They are important in maintaining the reputation of and confidence in the entire health care system..." (F, 4th year).

- "...mainly to distinguish urgent from non-urgent cases ...; their role is to provide the fastest possible assistance to people in their environment, which is distant from a major center...; acting primarily as a filter..." $(\mathrm{F}, 4$ th year).

\section{Opinions on type of work in rural practice}

Students saw the work of doctors in rural practice mainly as the typical work of family doctors. At the same time, they 
observed differences compared to doctors working in cities. Doctors in a rural setting also carry out work that does not fall within their service task profile, e.g. advising on legal matters, providing psychological support and resolving family problems. Students saw the activities of doctors in rural practice as diverse and varied, overlapping with other medical specialties. Students also emphasized the view that rural doctors were underpaid and under-appreciated by colleagues from other medical disciplines.

- "...in my opinion, they must often take on the role of doctors of other specialties, as people who live in rural areas do not regularly visit other doctors..." (M, 4th year).

- "...due to lack of time, their work cannot be carried out with such quality as would be necessary..." (M, 6th year).

\section{Advantages of working in a rural practice}

The advantages of working in a rural environment, as stated by the students, could be divided into two main groups: (1) personal advantages, e.g. benefits associated with the lifestyle of an individual, and (2) professional advantages, e.g. those associated with work in the countryside. Among the advantages related to personal reasons, the most prevalent reason was greater appreciation of the working and living environment as a personal value. Students also appreciated the peace and tranquility that is associated with nature and the environment in which the doctor lives. Among the advantages of working in rural areas, students mainly listed organizational benefits, such as those associated with smaller work teams, better communication and organization and a less branched hierarchy. Other perceived positives were a better understanding of the patient, their habits, family and social environment. Another advantage some students reported was the diversity in work, knowledge and practice.

- "...sense of connection with community, a certain respect that doctors receive in rural areas, better working hours, less critical situations..." (F, 3rd year).

- "...advantages include good knowledge of patients, especially their personal characteristics and family/social conditions, which may have a significant impact on the development of the disease ... work in an environment that is generally peaceful, less polluted and more tranquil..." (M, 3rd year).

\section{Disadvantages of working in a rural practice}

Among personal disadvantages, students emphasized distance from cities and social events and the slow pace of life in rural areas, which also limits the opportunity for personal and professional development. There is also less privacy, which can blur the boundaries between professional and private life. Students also mentioned the poor salary of doctors in rural areas for the job they do as a disadvantage.

When asked about disadvantages regarding work, students mostly emphasized the greater strain at work due to the large number of patients, a larger number of elderly patients with chronic diseases in advanced stages, inadequate working hours, distance from major medical centers and working in isolation without the possibility of consultations. Equipment and the possibility of diagnostics are also limited. Some saw a disadvantage in the repetitiveness of work, as well as the lack of appreciation of rural doctors' work by colleagues.
- "...too little appreciation and underestimation from other specialists and people. Large involvement in the patient's life, attachment and personal contacts can lead to burnout, less privacy, more difficult to separate private life from work..." (F, 4th year).

- "...inadequate working hours, greater work load, lower possibility of professional and personal development..." (F, 3rd year).

\section{Opinion on the type of doctors working in rural practice}

Students were asked about their opinion on what type of doctors would choose to work in rural practice. Among the positive comments, students described rural doctors as versatile, knowledgeable, resourceful, optimistic, hardworking and smart. They regarded these doctors as having a lot of knowledge that is not just limited to medical work and decision-making in the clinic, but that they are also well integrated into the local community and know a lot about their patients.

Among the negative comments, some students saw rural doctors as unambitious, elderly and as doctors who work in rural practice because they did not get a better job elsewhere.

\begin{tabular}{|l|l|}
\hline \multicolumn{2}{|l|}{ Table 3. Opinions about type of doctors } \\
\hline Positive & Negative \\
\hline Versatile & Unambitious \\
\hline Knowledgeable & Elderly \\
\hline Resourceful & Cannot get job elsewhere \\
\hline Optimistic & \\
\hline Hard-working & \\
\hline Smart & \\
\hline Integrated in local community & \\
\hline
\end{tabular}

-"...some are overloaded with work and some are bored..." (F, 6th year).

-"...older and experienced doctors who invest a lot of time and effort into their work outside of working hours..." (M, 3rd year).

\section{Conditions under which students would work in rural practice in future}

Students stated different conditions under which they would decide to work in rural practice. They can be divided into organizational, which includes rural practice organization, infrastructure and equipment of facilities, and local, which are associated with the place of residence and personal conditions.

Among organizational reasons, students emphasized heavy workload, an adequate number of patients, suitable working hours and flexible schedules.

Among infrastructural conditions, they emphasized an adequately equipped practice with easy access to a basic set of laboratory tests. They also expect suitable premises for work and an off-road emergency vehicle.

Among the reasons related to the place of residence, students emphasized adequate infrastructure in the form of educational institutions, post offices, banks and places to socialize being easily accessible. Proximity to a large city, good road connections and a low cost of living are also important. 
Among the reasons related to personal working conditions, students emphasized enough free time to engage in leisure activities. Important for them was also the possibility for employment for their partner and the short distance between their place of work and home.

- "...l would decide for work if there was a wellequipped practice available close to the city, a nice environment and climate, if there were enough leisure activities..." (F, 6th year).

- "...appropriate work that corresponds to my personal preferences and specialization, reasonable working hours, a limited number of patients, sufficient wage..." ( $M$, 3rd year).

\section{Curriculum and electives}

$15(71 \%)$ of surveyed students agreed that they would prefer more emphasis on rural medicine in the curriculum and extracurricular activities. Students primarily want to learn how to deal with patients using limited diagnostic options. In addition, they also want more opportunities to practice and perform research on the topic of rural health. They also proposed more lectures about medical psychology in the context of rural medicine.

- "...it is not suitable for me personally, since I would lose lot of time and fuel is not cheap...; if somebody covered these costs of transport, for example the medical school, then I would definitely be interested..." (M, 6th year).

_ "...based on limited possibilities for diagnostics, more emphasis could be given precisely on the decision-making process, clinical tests and diagnostics..." (F, 3rd year).

\section{Scholarship provided by rural practice}

If a scholarship to become a rural practitioner would be offered to them, an equal number of students would accept, decline or potentially accept the scholarship, depending on other factors. The decision would mainly depend on the location of the scholarship provider and if it were tendered to the desired specialization. Some would take the scholarship only if they urgently needed the money.

- "...l would never choose my place of work on the basis of the scholarship provider. I would rather not have this money than work somewhere where others say I should work..." ( $\mathrm{F}$, 3rd year).

$$
\text { - "...maybe, depends on location..." ( } \mathrm{F} \text {, 6th year). }
$$

\section{Discussion}

\section{Discussion about methodology}

Data about the opinions of students was acquired through an online questionnaire, which was sent to students who had expressed interest in the topic of rural health. The survey included non-standardized, open-ended questions. In terms of gender diversity, the sample corresponds to the male-female ratio at the faculty.

The data was analyzed by a single researcher. The purpose was to collect different opinions, and data was collected for each question from the questionnaire. For each question, the opinions were grouped by similar and recurrent themes.

\section{Discussion of results}

\section{Associations}

Students associate working in rural areas with a typical romantic image of the countryside, which is quiet, clean and where the pace of life is slow. In Slovenia, there are differences in the countryside, with some areas having the appearance of typical rural villages, but which are otherwise very close to major cities. The lifestyle in such places can be very distant from the typical rural lifestyle and is more similar to an urban lifestyle. The type of work in rural practice is associated with the typical image of a "village doctor". This is the image of a doctor who mastered different areas of medicine and does a lot of work alone, without referral to a higher level of care. Some students imagine rural doctors as tired and burned-out due to hard work. This image can be inaccurate, because doctors in rural areas do not necessarily have to be overwhelmed by a large number of patients, as the population in rural areas is actually smaller. There is a lack of additional studies to identify the actual workload of rural doctors in Slovenia. The level of knowledge of doctors in rural areas varies among individual and, like elsewhere, is also associated with remoteness and accessibility of higher levels of care. A doctor who works in an environment where referral to a higher level of medical care is a less accessible option due to remoteness will have a wider range of knowledge. On the other hand, this will be different for a doctor who works in a rural area close to more urban areas with a higher level of care, because a referral is easier. Similar associations were found in a UK study by Deaville et al. [9]. These were similar to an Australian study which identified four social and work factors associated with the attitudes of health care students to living and working in a rural area [10].

\section{Role of rural practices in the medical system}

The role of rural practices in the context of the medical system is valued very highly by students. The role of rural practices is seen to be mostly the same as the professional role of family medicine as a science, e.g. treatment and prevention of disease. This role can be typical for family medicine practices regardless of location. As a specific role in which rural practices differ from urban practices, students consider rural practices as irreplaceable for the rural population in terms of provision of emergency and primary care. The reason for this is that the majority of the rural population accesses health care services through rural practices, as institutions of a higher level of medical care are logistically more difficult to access [11]. Evidence of the highly praised role of rural practices is also found by other studies, in which students agreed that the delivery of health care in rural areas is important [12]. A positive attitude towards health care services in rural areas was presented in a study by Azer et al. [13].

\section{Opinion on the type of work in rural practices}

Students see the type of work in rural practices as a characteristic work of family doctors, which does not differ much from similar work in an urban environment. However, the prevailing opinion is that in order to work in rural areas, doctors need a broad set of knowledge and skills, which family physicians in urban areas do not need. This can be concluded from students' belief that rural doctors perform diverse services, not only strictly medical (e.g. social services), due to the smaller number of other available institutions and the greater distance to them. This can also be associated with the previously mentioned distance to secondary and tertiary level health care in rural areas. There is a lack of additional studies to compare the salary of rural and urban doctors in Slovenia. Similarly, an Australian study shows that students imagine rural doctors and their work to be different from an urban setting [14].

\section{Advantages of working in a rural practice}

Among the advantages related to personal reasons, students often mentioned greater appreciation from patients in 
rural areas. This can be attributed to the nature of work of the family doctor, who has the ability to monitor the patients long term and to become more familiar with them. It is assumed that doctors in rural areas are still highly praised in the community, especially among the elderly. In addition, a doctor in a rural area may be the only contact with the health care system and may represent an authority in the field of health, which is another reason why they are highly valued in the community.

Rural areas are associated with cleaner air and their distance from major roads and factories. The pace of life in rural areas is slower and more relaxed. This contributes to more time for family life and the serenity that reigns in these communities.

The organizational advantages of work in a rural practice are important for students. It is assumed that working in smaller teams with a less branched hierarchy contributes to less competition, higher integration and better cooperation. The advantage of better and lengthier knowledge of the patient allows for easier diagnosis of certain diseases, especially hereditary or those associated with lifestyle. The patients build a more personal relationship with the doctor, which leads to greater trust. As stated previously, advantages are also associated with the typical image of a "village doctor", a doctor whose expertise covers a wide area of medicine and includes the capability of carrying out a number of minor medical procedures. For some students, this represents an attractive challenge and an interesting test of knowledge. All of the stated advantages are very similar to the opinions found in a survey exploring the opinions of German practitioners [15]. Similar statements were found by an Australian study, where students listed teamwork as a benefit of rural settings. They also valued the friendliness and welcoming attitude of the local community and staff [16]. The Australian study by Azer et al. identified similar advantages of a rural environment, e.g. greater appreciation by patients, a friendly environment, less pressure and stress [13].

\section{Disadvantages of working in a rural practice}

Students see the disadvantages of working in a rural practice mainly in relation to a larger number of patients visiting a single doctor. As mentioned before, an unanswered question is whether the workload of doctors in rural practices in Slovenia is larger compared with doctors in an urban environment. Students also emphasize the disadvantage of exhausting work in rural areas due to the greater number of older people who come to the doctor when the disease is already advanced. This is an obstacle for high quality treatment. Inadequate equipment in clinics and poorer access to diagnostics is an understandable disadvantage of rural practices. This complicates the diagnosis and work for young doctors with a lack of experience and eagerness to rely on the modern diagnostic procedures they became used to during their studies.

The lower appreciation of the work in a rural practice by other doctors is a disadvantage, which is associated with a lower possibility of professional development.

Personal disadvantages are mainly social and professional isolation. It is important for young people that the infrastructure of the place of residence provides social and professional development, which are important factors influencing quality of life. Their place of residence needs to match their values and interests [17]. Another interesting uncovered disadvantage is the lack of privacy, which is typical for rural life. This reflects the assumption that the work of a doctor in a rural area comprises not only work during working hours, but also comprises a rural way of practicing medicine, where the doctor stays more connected with their patients in their spare time as well. As stated previously, the disadvantage of lower wages for rural doctors is an open question, since there is no data to support this in Slovenia. Similarly to the advantages, all of stated disadvantages are very similar to those found in a study exploring the opinions of German practitioners [15]. The concern over a limited social life in a rural setting was also expressed by students included in other studies [16]. The Australian study by Azer et al. identified similar disadvantages, e.g. lack of facilities, afterhours workload, lack of consultation [13].

Opinion on the characteristics of doctors working in rural practice

Students' opinion about the characteristics of doctors working in rural practice is mainly positive. Students see doctors as "rural heroes", who possess a broad spectrum of knowledge and skills necessary for work in a rural area.

However, some students see rural doctors as unambitious, which can be explained by the fact that working in rural area is not considered a desirable medical career among students. In a study done by Eley et al., similar positive opinions were found, in particular a broad knowledge base to deal with a larger variety of clinical work [14].

It is important to emphasize that a student's opinion about rural doctors can be very subjective and based on personal experience with individual doctors.

Conditions under which students would work in rural practice in the future

Organizational conditions given by the students are mainly related to the organization of work in a way which avoids work overload. This can be attributed to the association of heavy, burdensome work in rural areas. Students are aware of concepts such as stress and burnout and of the importance of work organization which prevents them.

Infrastructural reasons are related to the image that rural clinics are badly equipped. During the studies in medical school, a great emphasis is placed on modern diagnostic possibilities, which are often not available in rural practices. Students are concerned due to their lack of experience, which is a prerequisite for such work. It is important to have a well-equipped rural practice, and additional possibilities, e.g. tele-emergency services, increase the likelihood of physicians entering and remaining in rural practice [18].

Among the reasons related to the place of work, students emphasized appropriate infrastructure surrounding the rural area. This is understandable, considering that students are young people who have high expectations regarding their quality of life. For the quality of life of young people, openness is important in terms of an infrastructure that enables social life, as well as personal and professional development.

In rural areas, there are usually less employment opportunities for the spouses or partners of doctors, especially those with higher education. This may be an important factor in making a decision on the place of residence and, consequently, employment.

Similar reasons were found in an Ontario study, which states that financial and lifestyle considerations are important influences on medical students' decisions to practice in rural communities [19], and in a review by Henry et al. [5]. One's place of origin is also very important, as illustrated by a study done by Walker et al., which shows that students from rural backgrounds were ten times more likely to prefer working in rural areas when compared with other students [20]. Additionally, similarities were found in a study on factors that would entice junior doctors to work in a rural practice: partner/family factors, professional support, career opportunities, specialty requirements and infrastructure and financial incentives [21]. A Ghanaian study found that students are motivated to study medicine by the desire to help others, but this does not translate into willingness to work in rural areas [22]. 


\section{Curriculum and electives}

The students generally expressed a positive attitude towards the idea that the program of study and extracurricular activities should place more emphasis on the field of rural medicine. Students are seeking more practical work, mainly due to the belief that a doctor in rural practice has limited diagnostic resources and must therefore heavily rely on their own diagnostic skills and ingenuity, which can be developed only through practice. Similar observations were found by other researchers [9].

Such practical work should be well structured and organized, since it is connected with greater financial and logistical issues [9]. Good protocols should also be developed [23].

As found by other studies, these learning experiences can lead to a change of attitude among students, and they ultimately enable a curricular renewal at the institutional core [24]. They can supplement one's initial interest in rural medicine [25].

As stated by Hurst, medical schools should make students more proficient in rural medicine, require rural rotation, raise the profile of rural medicine among the faculty and make the intellectual challenges and potential for excellence in rural medicine more visible [26].

Greater exposure of students to the rural environment is also supported by recommendations from the WHO in 2010, entitled Increasing access to health workers in remote and rural areas through improved retention. Three points of these recommendations speak for the education of students closer to rural areas, the exposure of students to a rural environment and adapting the curriculum to the needs of rural areas [27].

\section{Scholarship provided by rural practice}

The location of the scholarship provider, desired specialization, work commitment and financial benefits are similar to the circumstances noted in an Australian study by Devine et al. [28] and Royston et al. [4]. As stated by Hurst, the rewards of outpatient family practice and rural medicine, especially the non-financial ones, are not likely to be visible from a distance [26].

The Slovenian system of the Human Resources Scholarship is based on providing scholarships for a specific workplace in a specific region. Students can apply for scholarship and sign a contract which obliges them to work at a specific workplace for the same amount of time as they receive the scholarship [29]. A scholarship in the student's hometown or place of study is a benefit, since it represents an additional financial incentive to work in a place where the student is currently living. On the other hand, applying for a scholarship in a more remote location can sometimes only be for financial reasons. The question remains whether the students would work in these places for a longer period of time or just for the number of years that was specified in the scholarship contract. Very often it happens that scholarship students go elsewhere, as has occurred in the Koroska region, where they have lost more than half of the expected future doctors who were receiving scholarships [30].

\section{Limitations}

The research has several limitations. The number of interested students who responded to the questionnaire was low. The purpose of the research was to gather as many different opinions as possible. The research could be more viable if the number of respondents was higher.

Another limitation is the analysis of qualitative data. Due to the lack of qualified researchers, the study was performed by only one researcher. This can influence the objectivity of the results. Analysis of data by two researchers would contribute to the greater strength of the study.

\section{Conclusions}

Students expressed interest in rural medicine, but are concerned about opportunities for personal and professional development in rural areas.

Students are interested in spending part of their medical training with doctors in rural practices, mainly in the form of practical work, electives or student projects in the countryside.

System of staff scholarships needs to be strengthened, especially in terms of the recruitment and retention of scholarship recipients in the establishment which provided the scholarship. The reasons given by students as important when choosing a place and institution of work need to be included in the promotion of employment in rural practices.

Further studies are needed on the topic or rural health in Slovenia, and their main purpose should be to get exact data on the state of rural practices.

Acknowledgment. The author expresses his great gratitude to the late Professor Janko Kersnik, MD, MSc, PhD, for his mentorship.

Source of funding: This work was funded by the author's resources.

Conflict of interest: The author declares no conflict of interests.

\section{References}

1. Muzevič, I. Predlogi sindikata PRAKTIK.UM za krepitev družinske medicine in ohranitev vzdržnosti zdravstvene blagajne. Ljubljana; 2012 [cited 20.12.2013]. Avaliable from URL: http://www.sindikat-praktikum.si/index.php/dokumentacija.

2. Buzeti T, et al. Neenakosti v zdravju v Sloveniji. Ljubljana: Inštitut za varovanje zdravja Republike Slovenije; 2011.

3. Peklaj S. Analiza ankete o potrebah ambulant na ruralnih območjih. Ljubljana: Ministrstvo za zdravje Republike Slovenije; 2011 [cited 20.12.2013]. Avaliable from URL: http://www.mz.gov.si/fileadmin/mz.gov.si/pageuploads/Posveti_konference_2011/Ruralne_ambulante_150711/Analiza_vprasalnika_15.7.2011-Peklaj_Zdruzljivostni_nacin_.pdf.

4. Royston PJ, Mathieson K, Leafman J, et al. Medical student characteristics predictive of intent for rural practice. Rural Remote Health 2012; 12: 2107 [cited 20.04.2014]. Available from URL: http://www.rrh.org.au.

5. Henry JA, Edwards BJ, Crotty B. Why do medical graduates choose rural careers? Rural Remote Health 2009; 9: 1083 [cited 20.04.2014]. Available from URL: http://www.rrh.org.au.

6. Rabinowitz HK, Diamond JJ, Markham FW, et al. Critical factors for designing programs to increase the supply and retention of rural primary care physicians. JAMA 2001; 286(9): 1041-1048.

7. Rabinowitz HK, Petterson S, Boulger JG, et al. Medical school programs to increase the rural physician supply: a systematic review and projected impact of widespread replication. Academic Medicine 2012; 87(4): 488-492.

8. Chater A, Rourke J, Couper I. WONCA Rural Medical Education Guidebook. World Organization of Family Doctors (WONCA): WONCA Working Party on Rural Practice 2014 [cited 13.04.2014]. Avaliable from URL: www.globalfamilyldoctor.com. 
9. Deaville JA, Wynn-Jones J, Hays RB, et al. Perceptions of UK medical students on rural clinical placements. Rural Remote Health 2009; 9: 1165 [cited 15.11.2014]. Available from URL: http://www.rrh.org.au.

10. Adams ME, Dollard J, Hollins J, et al. Development of a questionnaire measuring student attitudes to working and living in rural areas. Rural Remote Health 2005; 5: 327 [cited 15.11.2014]. Available from URL: http://www.rrh.org.au.

11. Ridder HG, Miles MB, Huberman AM, et al. Qualitative data analysis. a methods sourcebook. 3rd ed. SAGE Publications; 2014.

12. Landy DC, Gorin MA, Egusquiza JD, et al. Medical student attitudes before and after participation in rural health fairs. J Res Med Sci 2012; 17(3): 298-303.

13. Azer SA, Simmons D, Elliott SL. Rural training and the state of rural health services: effects of rural background on the perception and attitude of first-year medical students at the university of Melbourne. Aust J Rural Health 2001; 9(4): 178-185.

14. Eley D, Young L, Shrapnel M, et al. Medical students and rural general practitioners: congruent views on the reality of recruitment into rural medicine. Aust J Rural Health 2007; 15(1): 12-20.

15. Natanzon I, Szecsenyi J, Ose D, et al. Future potential country doctor: the perspectives of German GPs. Rural Remote Health 2010; 10: 1347 [cited 5.12.2014]. Available from URL: http://www.rrh.org.au.

16. McAllister L, McEwen E, Williams V, et al. Rural attachments for students in the health professions: are they worthwhile? Aust J Rural Health 1998; 6(4): 194-201.

17. Tolhurst HM, Adams J, Stewart SM. An exploration of when urban background medical students become interested in rural practice. Rural Remote Health 2006; 6: 452 [cited 5.12.2014]. Available from URL: http://www.rrh.org.au.

18. Potter AJ, Mueller KJ, Mackinney AC, et al. Effect of tele-emergency services on recruitment and retention of US rural physicians. Rural Remote Health 2014; 14: 2787 [cited 5.12.2014]. Available from URL: http://www.rrh.org.au.

19. Jutzi L, Vogt K, Drever E, et al. Recruiting medical students to rural practice: perspectives of medical students and rural recruiters. Can Fam Physician 2009; 55(1): 72-73.e4.

20. Walker JH, DeWitt DE, Pallant JF, et al. Rural origin plus a rural clinical school placement is a significant predictor of medical students' intentions to practice rurally: a multi-university study. Rural Remote Health 2012; 12: 1908 [cited 5.12.2014]. Available from URL: http://www.rrh.org.au.

21. Rogers ME, Searle J, Creed PA. Why do junior doctors not want to work in a rural location, and what would induce them to do so? Aust J Rural Health 2010; 18(5): 181-186.

22. Agyei-Baffour $P$, Kotha $S R$, Johnson JC, et al. Willingness to work in rural areas and the role of intrinsic versus extrinsic professional motivations - a survey of medical students in Ghana. BMC Medical Education 2011; 11: 56-63.

23. Newbury JW, Shannon S, Ryan $V$, et al. Development of 'rural week' for medical students: impact and quality report. Rural Remote Health 2005; 5: 432 [cited 20.01.2014]. Available from URL: http://www.rrh.org.au.

24. Van Schalkwyk SC, Bezuidenhout J, Conradie HH, et al. 'Going rural': driving change through a rural medical education innovation. Rural Remote Health 2014; 14: 2493 [cited 20.01.2014]. Available from URL: http://www.rrh.org.au.

25. Jamar E, Newbury J, Mills D. Early career location of University of Adelaide rural cohort medical students. Rural Remote Health 2014; 14: 2592 [cited 20.01.2014]. Available from URL: http://www.rrh.org.au.

26. Hurst S. Eroding students' rural motivation: first do no harm? Swiss Medical Weekly 2014; 144: w14020.

27. World Health Organization. Increasing Access to Health Workers in Remote and Rural Areas Through Improved Retention: Global Policy Recommendations. Geneva: WHO; 2010.

28. Devine SG, Williams G, Nielsen I. Rural Allied Health Scholarships: do they make a difference? Rural Remote Health 2013; 13: 2459 [cited 20.01.2014]. Available from URL: http://www.rrh.org.au.

29. Javni sklad republike Slovenije za razvoj kadrov in štipendije. Kadrovske štipendije 2014 [cited 16.03.2016]. Avaliabe from URL: http://www.sklad-kadri.si/si/stipendije/kadrovske-stipendije/.

30. Celin M. Zdravstvo na podeželju: denar ni najboljša vaba. Delo 2013 [cited 20.12.2014]. Avaliable from URL: http://www. delo.si/zgodbe/nedeljskobranje/zdravstvo-na-podezelju-denar-ni-najboljsa-vaba.html.

Tables: 3

Figures: 0

References: 30

Received: 02.03.2016

Revised: 23.03.2016

Accepted: 11.04.2016

Address for correspondence:

Rok Petrovcic, MD

Faculty of Medicine

University of Maribor

Robova cesta 4, 1360 Vrhnika

Slovenia

Tel.: +38631215650

E-mail: rok.5rovcic@gmail.com 